\title{
Factors Affecting the Selection and Implementation of a Customer Relationship Management (CRM) Process
}

\author{
Regina Reicher, Ágnes Szeghegyi
}

Óbuda University Keleti Faculty of Business and Management, Institute of Enterprise Management Tavaszmező u. 17, 1084 Budapest, Hungary reicher.regina@kgk.uni-obuda.hu; szeghegyi.agnes@kgk.uni-obuda.hu

\begin{abstract}
The situation of Hungarian micro, small and medium-sized enterprises has become very difficult as the result of the economic changes of the recent years. The open European market, the economic crisis and the ever increasing competition demand fast reaction, creating a serious challenge for these enterprises coping with a lack of capital and other resources. Therefore, companies in the SME sector pay an increasing attention to serve their customers at a high level. In order to achieve this, they often seek an IT solution. Owing to these circumstances it is extremely important for the enterprises coping with harsh economic conditions to choose and implement the most suitable CRM IT solution quickly, efficiently and at the lowest risk of possible failure. This requires, however, the thorough knowledge of competencies of the organization, the wide range of solutions available on the market and adequate methodology which offers success for them. The present research aims to explore the factors affecting the decision-making process in the course of which the SME heads select and implement a CRM system. As the result of our research, the specification defined by experts and heads of user companies could be determined and classified.
\end{abstract}

Keywords: CRM implementation; CRM selection; factors affecting successful implementation; SME

\section{Introduction}

The complexity of internal procedures within enterprises has reached a level to where the use of IT management tools has become a necessity. Fast development of business IT has helped large enterprises to develop strong capacities within this area. In addition, the introduction of IT systems prompted the rationalization of internal procedures.

Small and Medium-sized Enterprises (SMEs) took an interest in using IT assets as well. The market offered them a solution in the form of business management 
software - even though these did not cover all operations of the company, just some fields, still, they have made some procedures more transparent and economic.

The primary goal of a CRM strategy is to develop and retain customer loyalty. Customer loyalty means a dedicated activity of the customer, which presupposes a positive customer attitude and a consequential customer behaviour.

The aim of using a CRM system is to organize the information arriving from various channels and to display it in a unified manner, sorting it by customers. Such cumulated customer history may improve the effectiveness of the company in the field of customer management and product development. It may define customer value and therefore it could further improve the effectiveness of handling important customers.

With this research we aim to concentrate exclusively on the Hungarian micro- and SME sector. The reason for this is the fact that large enterprises operate under different environmental conditions (capital strength and creditworthiness). We are not researching public service providers, Telecom service providers or companies in the banking sector, which are typical CRM users.

It is also relevant to mention that the number of CRM suppliers is rather large, and the competition in this sector undoubtedly strong.

In the light of the importance and relevance of the topic, we have set out the following aims.

- Analysis of the procedure and general issues of the implementation of a CRM IT system from the viewpoint of the supplier in case of SME users;

- Classification of the phases of the selection and implementation process, searching for common and different characteristics with the help of principal component analysis.

We expect that the results of the aimed research would help in identifying and organizing the factors within and surrounding IT suppliers and CRM buyer SMEs that influence the implementation and operation of CRM IT systems.

\section{The CRM System}

According to Rust [14] strategic actions aiming at the construction of personalized, long-term relations were observed on the B2B market for many years. Examples include, a global accounts director appearing in an independent position, client managers receiving managerial positions and products that are developed in order to meet the demand of a single client. Similar examples can be seen on B2C markets, too. There are also, some initiatives observed in 
multinational companies to improve the level of customer services, to map consumer needs and to develop the products or services according to the consumers' requirements.

Mester says that two important trends were involved in the development of CRM. One of them is the decreasing differences between products - this forces the market actors to distinguish themselves from their competitors by tailoring their products. The other one is the development of information technology which enabled the companies to collect and analyze the data about the clients with the help of various software products. [11]

Thus the operational strategy and the marketing concepts of companies changed fundamentally. When the product is not in the focus of marketing any more, the aim is not the sale of a certain product in any quantity to anyone with the maximum profit attainable, but the consumer is being put in the crosshairs of marketing. The common objective of marketing experts, salespeople and the company is to sell the most different products to the consumer at the highest possible profit, to the satisfaction of the customer. [7]

This change of attitudes describes the strategy of the companies fighting and surviving in the current economic crisis. This attitude affects the business activities and all the organizational units of the company, the areas of finance, marketing, logistics, quality assurance, information technology and sales, as well as all the levels of staff from the senior executives to the direct customer service representatives in the front office.

One of the main possibilities of CRM systems is the preparation of customer analyses. By using the database, the system is able to create client groups on the basis of given parameters, to make data analyses and to calculate client value. [3]

If we intend to group the functions, three areas can be distinguished. There are internal procedures where the aim is to support work-flow and to track staff performance. There are customer processes where the help-desk function and customer history is managed. And, finally, there are the statistics which include: customer segmentation, market basket analysis, attrition analysis and risk analysis.

The collected data can be analyzed, reports and statement can be compiled on the basis of different filters and complex conditions. That data is a great assistance in drafting forecasts, in the planning process, during product development and in the overall development of the whole organization. It may also help find and mark the path to be followed as management is not left to groping around in the dark.

There are several definitions of CRM in the literature. Approaching it by focusing on its content, in a functional manner, or from an IT viewpoint, company experts defined the features of CRM strategy and software differently. 
According to Mátyás Gritsch CRM is „A customer-oriented philosophy which based on modern information and communication techniques - aims to form profitable customer-relations in the long run”. [4]

Adrian Payne says that „CRM is a strategic method, the aim of which is to create higher shareholder value by developing proper relations with customers and customer groups. The CRM combines the possibilities of information technology and relationship marketing strategy in order to form profitable and long-term relations. It is important to note that CRM ensures wider possibilities for the use of data and information in order to reach better understanding of customers and to realize relationship marketing strategies at a higher level. This requires the integration of people, actions, processes and marketing possibilities across several functions which are enabled by information, technology and applications." [12]

There are a number of other definitions, however, we can conclude that some key concepts emerge in all of them. All the definitions discuss the concepts of strategy, technology, client, organization and cooperation. It is obvious that the CRM definition can be drafted in several ways, these will differ only in regards to the approach but the above mentioned five key concepts are the same. It is also clear that the role of the technological framework, the information technology solution is the support of a CRM strategy with a modern tool. Furthermore, availability and implementation of a CRM philosophy is not required for to ensure a high-level of operation of customer services within a given company. The operation of a CRM IT solution is based on the customer strategy of the company and should support it."The CRM is a company-wide, customer-oriented strategy which - in order to meet customer needs as effectively as possible - integrates the business processes into an IT solution representing the latest technology built on a database which contains all the data of customers. The IT support and the unified database enable the automatization of customer procedures and the processing of customer data in order to maximise profit. The human factor is a particularly important element of customer relations treatment." [10] 


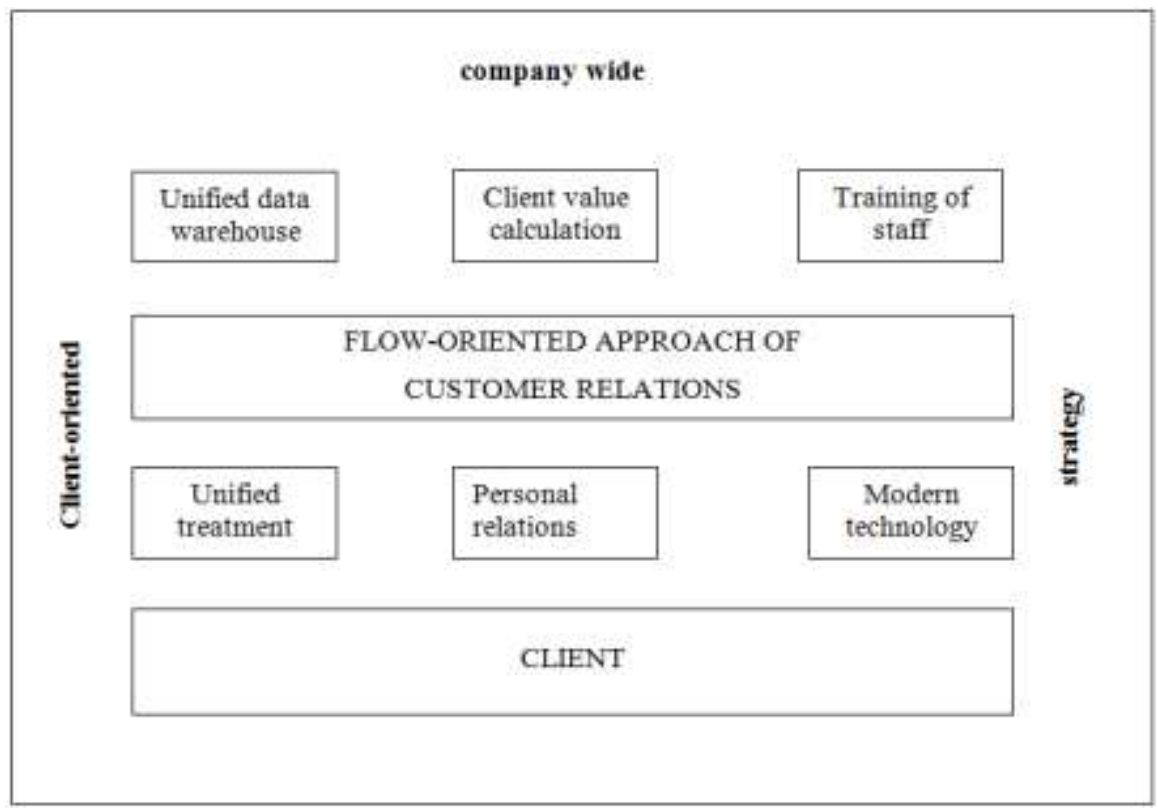

Figure 1

Comprehensive approach of customer relations [10]

\subsection{CRM Types}

From an information technology viewpoint, a CRM is a customer-oriented ebusiness solution. The CRM is basically built on an information database or data warehouse to which internet applications are connected. Its aim is to collect and analyse available data about customers in order to obtain a considerable volume of very valuable information about their purchasing habits, buying preferences and thus to determine the group of the most important clients.

On the basis of the usual classification offered by references, the CRM systems can be organised into three large groups on the basis of their functions and tasks within the company. These typizations are the most frequent on the distributors' market, too.

Operative CRM is the part of the system which ,deals with the automatization of business processes including front office costumer contact points. These areas apply the automatization of sales, marketing and help-desk services. Traditionally the operative CRM has a substantial share within corporate costs because a lot of companies do develop and utilize call centers and sales automatization systems. Consequently, the suppliers of CRM systems try to offer more and more types of alternative CRM-solutions". [12] 
Hetyei adds that this system controls and synchronises the client interactions in the field of services in addition to marketing and sales. He underlines the importance of recording all the customer data at the place where it arises and to make it available where and when it is needed. Front office staff and the staff of customer contact points belong to this function. [8]

MESTER, however, also draws attention to the fact that the operative CRM systems can display a wide range of client data but are not suitable to analyse them." [11]

Thus, in addition to the software solution providing operative functions, it can be necessary to use analytical CRM, which ,includes the recording, storage, organisation, analysis and use data arising during the daily operation of an enterprise. The integration of analytical CRM solutions with operative CRM solutions is an important aspect." [12]

Hetyei says that - in order to enhance the loyalty of profitable customers analytics helps the optimisation of information sources by organising customers according to different aspects, customer segmentation, analysing client migration or by defining the target group of marketing campaigns. It enables the company to carry out analysis with marketing purposes. Moreover, it provides a way to make analysis concerning cross-sales, analysis regarding product affinity, to use customer value calculation models, to apply attrition models and to operate campaign management solutions. [8]

According to Mester, who examines the analytical tool with an IT approach ,the data warehouse and all the related analysis tools can be actually defined as analytic CRM. What makes the totality of tools become a solution, is the repeatedly mentioned integration among them which - in an ideal case - hides the limits of the individual tools from the user and the preliminary, broadly tailored business intelligence - at least at a sectoral level - which provides solid basis for the solution of problems related with the information needs of the company." [11]

$>$ In addition to these, there is the collaborative CRM which "means the use of services and infrastructure and creates relations between the company and the multichannel sales system. This system connects the customers, the company and the employees." [12]

Hetyei adds that the collaborative solution enhances cooperation with suppliers, partners and customers in order to refine processes and to serve the needs of customers. The collaborative CRM extends communication with clients to all the marketing channels, for example - in case of a bank - to bank branches, mobile bank services, internet and others. [8]

According to Mester, "the aim of collaborative CRM is to support the interactions between customers, suppliers, partners and company; as well as to distribute the customer information among the members of the corporation in order to create efficient communication and coordination and to fulfil the needs arising". [11] 
These boundaries blur in the practice. The individual functional types in themselves can operate less efficiently than when operating together. The usefulness of data collection by an operative CRM can be questioned if the user is not able to make analytics, reports, analyses and forecasts uitlizing them. As the philosophy of a CRM application permeates the entire company, it becomes clear that the company should extend it not only to the customers, but to the partners and staff as well.

\subsection{Implementation and Operation of a CRM}

If the company management makes a decision to implement a CRM software, the aspects of choosing the software do not always correspond to the real needs. The decision-making may be influenced by the size of the company, the special features of the industrial branch, financial possibilities and a lot of other factors. Thus the true needs are not necessarily reflected in the aspects of selection.

The implementation of CRM is a complex, long project task concerning multiple areas, in which the company staff and IT suppliers should cooperate. If the implementation of CRM is successful, it causes basic changes in the life of companies. Révész says that these changes mean increasing sales, growing satisfaction of consumers, specific decline of general and marketing costs, improvement and increasing efficiency of coordination among internal processes. [13]

Gritsch says that the starting point of CRM implementation must always be the description of strategic objectives of the company and the recording of customeroriented corporate processes. [4]

Payne is slightly more sophisticated when giving advice concerning the implementation of CRM. He gives high priority to making a survey at the company before the implementation to see how much they are prepared for CRM activities. In this phase it is determined at what level the company is in, concerning, the field of customer treatment and what are the basic requirements for implementing the CRM. The factors that could hamper the successful implementation project are mapped. For example, the lack of skills, inadequate data quality, lack of participation on behalf of the management or the insufficiency of performance measuring systems.

Alshawi et al. performed research concerning the factors which affect SME actors concerning the acceptance of CRM. The research has revealed that the data quality, the organisational changes and the technical questions basically determine the relationship to the system. [1] 


\subsection{Small and Medium-Size Enterprises in Hungary}

"The SME sector is one of the basic factors of economic growth in Hungary, and similarly to the developed countries of the world and Europe. The SMEs make up more than $99 \%$ of the total number of Hungarian enterprises." [2]

The economic austerity, the heavy fiscal adjustments and the impacts of the global economic crisis have affected the results of companies very strongly. The global economic crisis has had a determinant impact on the Hungarian companies as well. Therefore, the small and medium-size enterprises also face the problem of declining domestic consumption. In order to maintain the level of their revenues, they have to implement new tools and methods in order to remain competitive on the narrowing market.

The SMEs react to every economic event very sensitively. All the cyclical fluctuations can be felt significantly and can be measured immediately in revenue and profit fluctuations. Since the economic environment is not permanent, the responsibility and the role of management becomes of exponential importance in this sector. The permanently changing environment, however, has made this sector rather flexible. The SMEs specialise, change their profile and corporate form more easily and they have a simpler organisational structure than large-scale companies.

The income generation of small and medium-size enterprises is more balanced than that of the large-scale companies. This leads to the conclusion that large-scale companies have a primary role in the emergence and persistence of economic disparities. The employment structure in case of small and medium-size enterprises is much more balanced in regional terms than in the case of large-scale companies (2013). [21]

On the basis of the flash report on competitiveness, made by Chikán et al. in 2010, it can be concluded that the ratio of external funds within the sources of the companies was $39 \%$ in 2004 . This ratio declined to $27.7 \%$ by 2009 . [5]

As a summary: the significance of small- and medium-sized enterprises cannot be neglected in the economic sector of Hungary. The Economic Development Operative Program (GOP), launched in the frames of New Hungary Development Plan and New Széchenyi Plan, was aimed primarily at the improvement of competitiveness of micro, small and medium-sized enterprises. Between 2007 and 2013, the SME sector could apply for IT development funds within the program. The aim of the program was to implement information and communication technologies in the business processes among companies and in services provided by the enterprises. Thus the enterprises could purchase and implement CRM systems as well.

According to the info-communication report of 2011 , only $10 \%$ of the surveyed companies applied for funding towards their planned investments. [16] 
Consequently, the preconditions of the appearance of CRM include information technology development as well. By analysing consumer databases it can be revealed which consumers bring profit and which do not, which services are high quality and which are not, and which marketing tools are efficient. The development of the internet was also a very strong influencing factor in the creation of CRM. The evolving e-trade has imposed new challenges for supplying and servicing companies.

\subsubsection{CRM as Competitive Advantage}

The representative research of Deák and Mester in Hungary warns that the Hungarian companies have not been mature enough for the implementation of CRM systems. Almost $45 \%$ of CEOs think that conscious customer management means registration. Two-third of companies do not examine the reasons for losing customers and $25 \%$ of companies do not follow the needs of customers - by their own admission. It is clear that the companies are not aware of their possibilities. [6]

However, by 2012 the situation was completely different. The developed Western societies were quick to realise the business opportunities in customer loyalty therefore they soon started to use CRM applications. Loyality 360 and SAS carried out a joint research program and examined 150 partner companies in the B2B and B2C market. They surveyed trends in the field of customer loyalty programs. The results were not very promising. Hardly a fourth of respondents regarded their program to be very good. Only 19\% considered the reduction of client migration a strategic task. In the communication with the customers, mostly email and social media were emphasised. Only $36 \%$ of respondents integrated the loyalty data with other client data. "Companies which determine the customer lifecycle and adjust their loyalty building and customer-retention activities to this are usually more successful - said Wilson Raj, the Global Director of Customer Intelligence at SAS. [20]

\subsection{Situation and Opportunities regarding the Competitiveness of SMEs in Hungary}

In Hungary, the small and medium-size enterprises are disadvantaged in regard to competitiveness compared to large-scale companies. Among other reasons, this is due to the lack of experts, lack of information and lack of corporate relations.

According to the competitiveness report of 2009, which is a research made among enterprises with at least 10 employees, it is common in many European countries that small and medium-size enterprises are not informed in the matters of the globalised world economy, they do not operate on international markets and are not confident enough to utilise the advantages offered by information and 
communication technologies (ICT). Among the examined countries in the region, internet use connected with internal business processes, the use of an ERP system, CRM, e-invoicing or digital signature is the least widespread in Hungary and is far below the EU average. (Figure 2)

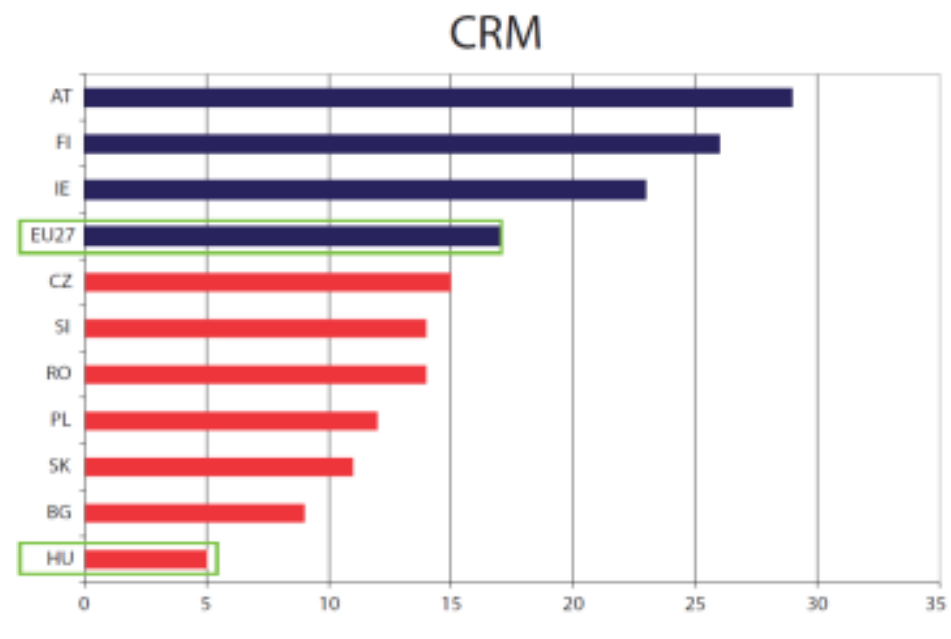

Figure 2

Expansion of CRM application in some EU member countries (\%) [15]

The info-communication report of 2011 states that there is a huge gap between large-scale companies and small, medium-size enterprises in many areas, including investments. At present, SMEs concentrate primarily on infrastructural elements in their procurements, like PCs, hardware equipment, network development, etc. Investments supporting business objectives do emerge among large-scale companies and, the only exception is perhaps the solutions ensuring internet presence. Still, there are only a few of these in the SME sector. [16]

The research made by the Association of Chartered Certified Accountants (ACCA) in the third quarter of 2011 has shown that the 661 small and mediumsized enterprises in Europe do not utilise the advantages of the digital world although they are aware of the cost-reducing impact of technological applications. [17]

One of the most important opportunities for recovery, from the crisis, is the search for new markets, especially towards the former Comecon countries and Visegrád countries. The reduction of product quality was regarded as the least appropriate alternative; this may be explained due to the strong pressure of market competition. The increase of demand and the reduction of costs also received high scores from the leaders participating in the research. These two areas could be supported properly by the implementation of a CRM system. 
According to a survey made by K\&H Bank in 2012, staff increase of SMEs stagnated. The heads of the SMEs said that they did not plan to hire new employees but did not want to fire anyone, either. $70 \%$ of respondents did not think of any expansion in regards to staff. The research showed different ratios in case of each size unit. $14 \%$ of micro-enterprises plan to hire new staff, this ratio is $22 \%$ in the case of small-scale companies and more than double, $30 \%$ in case of medium-sized enterprises. [18]

„The SME trust index research made by $\mathrm{K} \& \mathrm{H}$ among the chief executives of Hungarian SMEs in the second quarter of 2013 confirms that the investment willingness of enterprises exceeded its lowest point. The ratio of SMEs considering investment increased again in the first quarter of this year, at present $58 \%$ of them plan investments. As regards to the subject of investments, the IT development projects are still given priority". [19]

\section{The Situation in Hungary}

\subsection{Expert Opinions}

Since there is only a limited amount of literature on the implementation and operation of CRM systems, and these focus mainly on large companies, we performed a primary exploratory qualitative assessment. For the purpose of analysing the Hungarian CRM suppliers and users, we organised our research around the following two primary quantitative assessments.

The interviewed companies where characterised by two types of data. One was the number of clients, ranging from 3 to 30 . The other was the number of employees using the system. Here, the answers ranged from tens to 2000; these are approximations as no interview subjects had exact data. The answers were influenced by the fact that several companies could indicate only those clients in their answers who agreed to the use of their name as reference. Additionally, we observed another tendency: where the distributor has a foreign parent company, where that company offered remote access to its servers. This affects distributors active on the international market. For them it is hard to assess the number of domestic clients, as the parent company of the distributor may be offering remote access to a Hungarian subsidiary of a foreign client. The Hungarian CRM distributor will not know about this, as the license agreement was signed in the country of the parent company and access to the CRM system is provided from there.

Based on the literature we collected the critical points of CRM implementations, the general pitfalls, and then formulated the questions around these. 
By characterising the companies which implement a CRM, the respondents could not indicate a typical industry. They said to have clients both in the manufacturing and the services sector. They mentioned several motivation factors. It is primarily the market stress, the serious competition for clients that motivates clients to implement a CRM system as a need for marketing support arises. Another motivating factor was state aid offered to help IT projects, as well as the cases where sales experts with experience working in multinational companies appeared as new employees at SMEs.

There were great differences in product selection criteria in the case of various CRM purchasers. Often the client has no expertise in CRM systems and the connected IT solutions, furthermore they negotiate without bringing an advisor or expert along, and therefore their decisions on matters beyond the price will be subjective, superficial and often unfounded. The economic crisis had no positive results. Hungarian companies did not recognize the importance of customer retention in this situation. It is mainly companies with foreign parents who have their own implementation strategy. With these companies the implementation is performed following a central strategy developed based on international experience. US, German and Swedish parent companies require a high level of support in this area as well from the representatives in every country. Two of the respondents mentioned an implementation failure rate higher than 50\%. They concluded that more than $50 \%$ of their clients are not using the system after its implementation, regardless of education, good support and proper preparation. Everyday tasks and user resistance often raise serious issues in the company implementing a CRM. Another serious issue is raised by previously unplanned tasks becoming part of the everyday routine. Concerning the duration of the implementation, answers were spread out over on a broader scale, from the current week to one and a half years. Among the auxiliary services offered to the system, education and support were mentioned uniformly. Some mentioned advisory services at the development of the system plan, the assessment of existing hardware, the purchase of new hardware at a good price, periodical updates, patching and remote support.

Based on the experience of the IT suppliers it can be said that there are frequent cases where a CRM is implemented but not used; the reasons for this may be found in using a wrong procurement model. Usually the problem is caused by the non-optimal size of the procurement unit and its members not having the proper professional qualities. Choosing a supplier without an objective set of criteria is a very risky endeavour. The draft contract of the IT companies always foresees potential mistakes to be made by the purchaser; however, the purchaser often fails to contemplate its own potential and its limits. 


\subsection{Circumstances of Quantitative Research, Expert and User Sample Characteristics}

We contacted 57 distributors asking them participate with our expert questionnaire and to forward our user questionnaire to their clients. We received 31 expert answers and 104 user answers. This means that 54\% of the distributors (experts) have participated.

However, only estimations can be given on the percentage of user ${ }^{1}$ answers, as no exact data is available on the number of users that have received the questionnaire. The estimate value was calculated based on the total number of clients of the software distributors contacted; this is about 1300-1400. Hence, the user response ratio is about $12-13 \%$, which corresponds to the typical answer ratio of research conducted in the corporate sector.

The expert questionnaire was sent to 57 CRM system providers who are involved in the implementation, development and support of CRM systems. We paid attention to contacting a variety of experts which concerned the type of CRM systems implemented. Only three of them were of the previous interview subjects. Of the 31 experts, some were implementing installed software while others offered a cloud-based service. There was also a variety in the size of their clients, ranging from micro-enterprises to medium-sized or large companies. All software companies performed continuous development, and some of them offered individual development as well.

The 31 experts had a total experience of 170 years. The most experienced worked for 13 years as an expert and six of them had more than 10 years of experience; the average work experience is 5 and a half years. 11 experts worked on the implementation of 3 or more types of CRM systems, while 10 of them had experience with only one type.

The questions concerning CRM implementation can be organised in 3 clearly distinguishable groups on the basis of our previous experiences, the references and the interviews with experts. It is important to mention that human factors, the questions of IT support and corporate strategy play an important role. We tried to form the principal components in conjunction with these.

The opinion of respondents was measured in the following two questions, in a 10grade high measuring level interval scale

1 'Users' are here companies who have bought a CRM system from the software distributors. We asked each company to fill out exactly one questionnaire. 
16/22 Please evaluate on a scale of 1-10 how important you regard the following conditions for the SUCCESSFUL IMPLEMENTATION

1 not important at all, 10 very important

\begin{tabular}{|l|l|l|l|l|l|l|l|l|l|l|}
\hline & 1 & 2 & 3 & 4 & 5 & 6 & 7 & 8 & 9 & 10 \\
\hline mapping corporate maturity & & & & & & & & & & \\
\hline rationalisation of processes & & & & & & & & & & \\
\hline involving an independent consulting firm & & & & & & & & & & \\
\hline $\begin{array}{l}\text { development of customer management } \\
\text { strategy }\end{array}$ & & & & & & & & & & \\
\hline permanent management support & & & & & & & & & & \\
\hline exact definition of needs & & & & & & & & & & \\
\hline informing staff & & & & & & & & & & \\
\hline exact mapping of financial sources & & & & & & & & & & \\
\hline
\end{tabular}

17/22 Please evaluate on a scale of 1-10 how important you regard the following conditions for the SUCCESSFUL OPERATION!

1 not important at all, 10 very important

\begin{tabular}{|l|l|l|l|l|l|l|l|l|l|l|}
\hline & 1 & 2 & 3 & 4 & 5 & 6 & 7 & 8 & 9 & 10 \\
\hline $\begin{array}{l}\text { proper training during the } \\
\text { implementation }\end{array}$ & & & & & & & & & & \\
\hline $\begin{array}{l}\text { proper test running during the } \\
\text { implementation }\end{array}$ & & & & & & & & & & \\
\hline permanent feedback to the management & & & & & & & & & & \\
\hline $\begin{array}{l}\text { permanent system supervision by } \\
\text { supplier }\end{array}$ & & & & & & & & & & \\
\hline defining an authorisation system & & & & & & & & & & \\
\hline using a correct database & & & & & & & & & & \\
\hline $\begin{array}{l}\text { client meetings organised by supplier, } \\
\text { dissemination of information }\end{array}$ & & & & & & & & & & \\
\hline
\end{tabular}

The factor or principal component analysis is important because it reveals the hidden interrelations within the answers of the respondents. The characteristics belonging to one factor are linked in the mind of respondents as well, therefore they cannot be treated separately in the product policy. The high-weight variable is an important element of the factor or principal component, but to decide what is regarded as a high value the factor weight table is being used. [9]

Based on the main component analysis we could define three well separable components that are of great importance for our respondents and belong together according to their evaluation (Figure 3 ). 

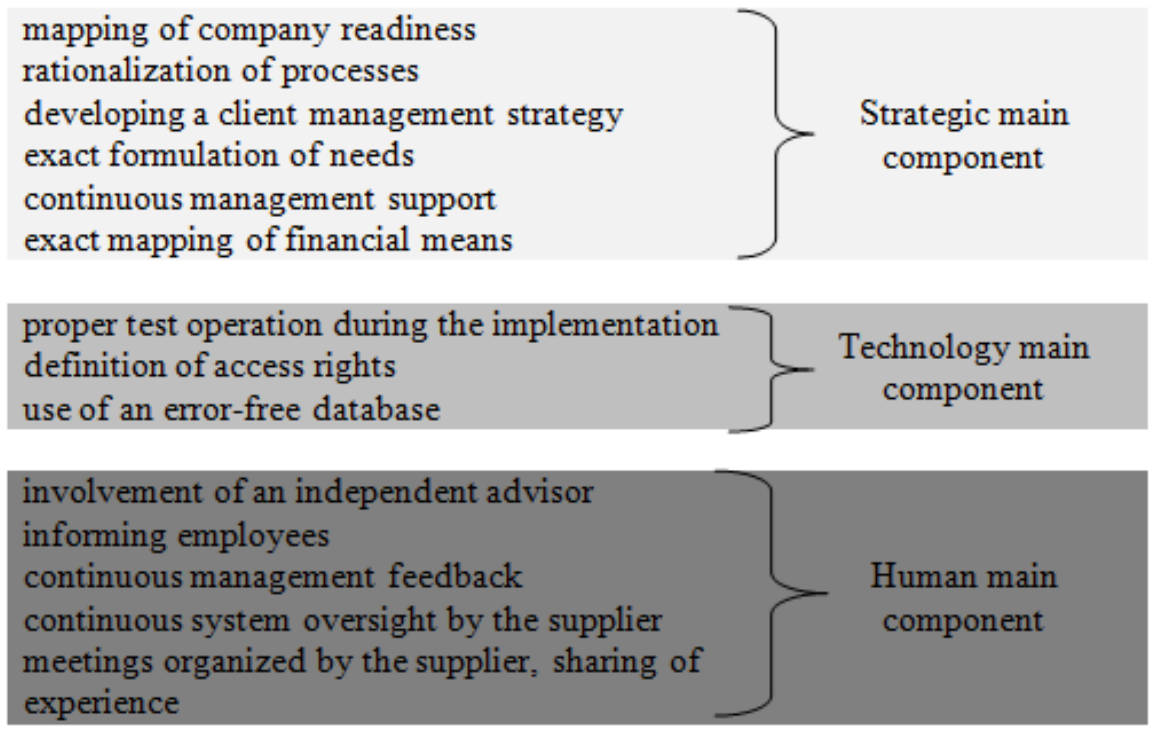

Figure 3

Results of the main component analysis

The examination and analysis of the final model seems thus to verify our original hypothesis that based on the answers of the supplier and the purchaser side, three sets of variables can be separated that are not correlating to each other and keep the information content of the different variables to the greatest extent. These three sets of variables represent the groups of human, strategic and technology variables. Thereafter, the attitude of the respondents can be examined alongside these components.

During our research we looked for the answer to the question what similarities there are between the views of suppliers and purchasers on the decisive reason for choosing a specific CRM and the motivation factors for the implementation.

Based on the answers of the supplier side and the purchaser side, three sets of variables can be separated: human, strategic and technological factors. The results of our questionnaires show that the (human, strategic and technological) factors defining the preparation and the implementation can be identified among the Hungarian suppliers and purchasers.

Identifying the (human, strategic and technological) elements of preferences in the preparation and implementation habits, effecting the decisions of Hungarian CRM suppliers and purchasers, give basis for efficient planning and implementing related to the preparation and the implementation.

Based on the results of the research we have proved that these factors play an important role in the success of the implementation for the respondents. The 
examination was performed using quantitative methods: main component analysis and component testing.

\section{Conclusions}

Having mapped the IT implementations it can be said that CRM implementations are mostly characterised by the feeling of failure from the side of both the supplier and the purchaser. The number of implementations does not decrease despite these feelings of failure and experts hope for a slow increase as a result of the improvement of the conditions after the waning of the economic crisis. During our research we could not aim to have a representative sample as no data is available on the statistical population. Based on the estimation of the experts, we can estimate that the yearly number of CRM implementations is 10 to 20 . This is, however, the number of systems actually needing an implementation. Presently, the spreading of cloud-based systems increases and even multiplies this number. However, these software solutions often do not provide proper CRM background service, only sales support, which is only a fraction of the tasks of a CRM.

No reliable data is available either on the supplier or the purchaser market. Therefore the views of the two sides of each other are based only on experience. Even if the suppliers (understandably) have more experience, this experience cannot be generalised to cover the entire purchaser side. One of the aims of our studies was to reveal the real motivation factors behind the choice and implementation of a CRM system and to compare this to the picture developed by the supplier side.

In the next part of our research principal component analysis was used on the views of the respondents on the preparation and the implementation, where they assigned a value of importance to the various tasks on a scale of 1 to 10,1 being the least important, while 10 being the most important.

The explained variance of the various principal components is split roughly and proportionately. Of course the results of the survey cannot be considered as a basis for conclusions for the entire domestic market given the deficiencies of the sampling; however, the general trends can be shown based on the answers of the suppliers and the purchasers.

It can be stated that the respondents divide the procedure of the preparation and the implementation into 3 main parts. The first contains steps containing strategic issues, involving the rationalisation of processes, the exact definition of demand, the development of a client management strategy, the mapping of company readiness and the exact mapping of financial potential. Although the weight of the various factors does not show large differences, the sequence here is not chronological, but that of importance based on the factor weights.

The second main component contains technology issues, involving the use of an error-free database, the definition of access rights and the management of the test 
operation during the implementation. The order here again shows the order of the score values.

The third main component contains the human factors. In the order of factorial weight these are: client meetings organised by the supplier, experience sharing, continuous management feedback, continuous system overview by the supplier, continuous management support and the involvement of an independent advisor company in the process of the preparation and the implementation.

These interrelated elements extend beyond the examined stages. The groups formed of the various variables are independent of the stage of the implementation in which the given task arises. However, the technology component is an exception to this, as its appearance only makes sense after the selection.

Our research has proven that the implementing side suffers a serious lack of professional expertise. The methodical deficiencies of the supplier side are not helping in the solution of this issue. Furthermore, the supplier side has a superficial knowledge about the motivation and demands of the implementing side; therefore even if they have a methodology it may not put the emphasis on the proper points.

The results of principal component analysis have highlighted that the experts have different attitudes, they attach importance to different areas. Therefore later we would give priority to performing segmentation with the help of cluster analysis. It may help - after the survey made among existing staff - to form expert pairs to support the implementation project who can facilitate the success of the project by complementing each other. Thus none of the areas would prevail and proper emphasis can be given to each part of the task.

\section{References}

[1] Alshawi, S., Missi, F., Irani, Z. (2011): Organisational, Technical and Data Quality Factors in CRM Adoption - SMEs Perspective, Industrial Marketing Management, Vol. 40, Issue 3, April 2011, pp. 376-383

[2] Bíró, P. (ed.) (2011): Company Management and Marketing in E-Ages, Tbálint Publisher, Törökbálint

[3] Bohnné, K. K. (2005): The Customer is Satisfied? Public Press Ltd., Budapest

[4] Chikán, A., Wimmer, Á. (2004): Business Glossary, Alinea Publisher, Budapest

[5] Chikán, A., Czakó, E., Zoltayné, P. Z. (ed.) (2010): Corporate Competitiveness in Times of Crisis, Competitiveness Research Center, Budapest Corvinus University

[6] Deák, Cs., Mester, Cs. (2005): Change Management in the Backstage of CRM Projects, Business Studies, Volume 3, Number 1, pp. 101-112 
[7] Erdélyi, E., Kovács, B., Merényi, A., Számely, É. (2006): Experience of the Best Practice in CRM Implementation in Industry, T-Mobile, Telecom Hungary XVII. évf. 2006/3 pp. 16-23

[8] Hetyei, J. (2004): ERP systems in Hungary XXI. century, Computerbooks, Budapest

[9] Hoffmann, M., Kozák, Á., Veres, Z. (2000): Market research, Technical publisher, Budapest

[10] Mester, Cs. (2006): How to become a determining element of competitiveness of companies in the CRM? Management sciences XXXVII. year. 2006/ special issue pp. 87-97

[11] Mester, Cs. (2007): The power of CRM, or customer relationship management in the Hungarian general corporate practice, $\mathrm{PhD}$. Dissertation, University of Miskolc

[12] Payne, A. (2007): CRM handbook, customer relations on high level, HVG publisher Ltd., Budapest

[13] Révész, B. (2004): The Influence of CRM and E-CRM Systems on Customers' Opinion of a Company, $3^{\text {rd }}$ International Conference for Young Researches pp. 244-251

[14] Rust, R. T., Thompson, D. V., Hamilton, R. W. (2006): Do not over complicate this product! Harward Business manager, VIII. évf. 2006/9 pp. $50-59$

[15] Competitiveness Yearbook, GKI, 2009

[16] Hungarian Information and Communications Report 2011

[17] http://www.vallalkozas-online.hu/index.php?option=com_content\&task= view \&id=515\&Itemid=105

[18] http://www.marketinginfo.hu/hirek/article.php?id=24112\& referer_id=newsletter

[19] https://www.kh.hu/publish/kh/hu/khcsoport/sajtokozlemeny/2013/ 2013_II_negyedev/mersekelten_noevekv__beruhazasi_kedv.html

[20] http://www.sas.com/resources/asset/Strategic_Imperative.pdf

[21] http://www.kaleidoszkop.nih.gov.hu/documents/15428/123426/kkv12 